\title{
Reconciling disparate views on decadal climate variability from proxies and models
}

doi: 10.22498/pages.25.1.68

\author{
Toby R. Ault \\ Dept. of Earth and Atmospheric Sciences, Cornell University, USA
}

\section{Introduction}

Researchers studying decadal variability over the instrumental period are often confronted with two major obstacles. First, the observational record is short compared to the timescales of interest, sampling at best only a few realizations of decadal-scale phenomena (Meehl et al., 2009). Second, most climate variables include long-term trends driven by human activity (e.g., land use change, aerosol pollution, and of course the impact of greenhouse gas emissions), which sometimes mask decadal variability from natural causes. The climate research community therefore often turns to both paleoclimate archives of past changes, as well as multi-century integrations of general circulation models (GCMs). Both types of data can provide insights into the amplitudes, patterns, and plausible mechanisms of internal decadal variability, which could ultimately help inform and evaluate predictions of near-term climate evolution. In principle, proxy and GCM data should yield a consistent view of the climate system on these timescales. In practice, current paleoclimate data-model comparisons of decadal variability must contend with at least one of the challenges delineated below. To address these concerns, I submit several heuristic recommendations to help to identify fundamental similarities-and critical differences-between paleoclimate and climate model perspectives on decadal variability of the last millennium.

\section{(i) Paleoclimate archives filter climate variability in} ways that are difficult to quantify.

Most paleoclimate archives "redden" climate information by storing information from one time period to the next (e.g., Matalas, 1962; Evans et al., 2013; Ault 2013; Dee et al., 2015). This reddening, in turn, has the effect of amplifying decadal fluctuations in proxy records relative to their climatic drivers. Consequently, the mere presence of high amplitude decadal variability in a given paleoclimate time series cannot be taken as evidence of correspondingly energetic climatic variability (the details of this effect are considered extensively in Ault et al., 2013 and also Dee et al., in revision).

In addition to reddening the spectrum of underlying climate variables, many paleoclimate archives preferentially record information from certain seasons. For example, St. George et al. (2010) showed that treering reconstructions of North American PDSI (Cook et al.,
2004) exhibit variable seasonal sensitivity to temperature and precipitation depending on the region. In the US Southwest, for example, the PDSI is highly sensitive to winter moisture, while in the Pacific Northwest, it depends more strongly on summer temperature. These seasonal dependencies reflect, in part, the dependence of tree growth on different environmental factors during the seasonal cycle (St George and Ault, 2014), a finding consistent with basic dendroclimatological theory (Fritts, 1976). On interannual timescales, diagnosing the filtering effects of tree growth on climate input is relatively straightforward because data are annually resolved and overlap with the instrumental period. However, this problem has not been widely studied on decadal time horizons, and it remains a possibility that trees grow in response to different climate factors across timescales (e.g., Franke et al., 2013).

(ii) Forward models of paleoclimate archives might be biased by spatial and temporal patterns in GCMs. Given the tendency for proxies to redden and filter climate information, one might be tempted to simply run GCM output through "forward models" of various proxy systems and compare the resulting output with actual archives. Caution would be recommended for such an approach because models themselves exhibit systematic geographic and frequency biases. Consider a case in which a forward model of tree-ring growth is run to predict annual ring-width anomalies as a function of monthly temperature and precipitation (e.g. the "Vaganov-Shashkin-Lite" model of Tolwinski-Ward et al., 2011; VS-Lite). If this model were to be run with raw output from a GCM with a wet bias (as is common for the American Southwest), VS-Lite would produce simulations where tree growth is never limited by the availability of soil moisture, even during the "driest" year. Similar considerations apply to other types of proxy systems, and although standard bias-correction techniques are available for removing systematic model errors (e.g. Maurer et al., 2007), these tools have not been widely adopted for paleoclimate model-data comparisons.

(iii) Climate teleconnections are not necessarily stable through time. There are inherent biases in the structure of GCM teleconnections linking remote climate variations (e.g., in the Pacific basin) to the locations 
where there are paleoclimate records (e.g., the American Southwest). For example, Coats et al. (2013) found that El Niño/Southern Oscillation teleconnections in GCMs: (a) are not well simulated by some models in the American Southwest, and (b) are not always stable in all models from one century to the next. These considerations extent to decadal timescales and observations data; Newman et al., (2016) argued that the spatial pattern of the Pacific Decadal Oscillation (PDO) during the 20th Century might not be representative of decadal variability in that basin over the last millennium, and hence the teleconnections driven by this climate mode may have been different in the past. Consequently, both GCMs and proxies may be susceptible to aliasing by changes in the large-scale structure of processes that generate decadal variability.

\section{Suggestions to improve our understanding of decadal variability in proxies and models.}

The list of considerations above implies at least four key principles should be followed when attempting to characterize decadal variability in a given system or region using paleoclimate data and climate model output. These include:

1. Comparisons are likely to be most meaningful if reconstructed phenomena are compared with model phenomena (e.g., Fig. 1), as opposed to local or regional variations. Reconstructions of largescale climate modes tend to rely on networks of paleoclimate archives, often from different proxy types (e.g., Emile-Geay et al., 2013). Accordingly, such networks can minimize the effects of proxy filtering as well as differences in spatial scales between model grids and individual sites. Moreover, if teleconnection patterns change through time, a large-scale network of sites will be better suited to "see" the same phenomena even if its spatial imprint varies.

2. Decadal variability inferred from both paleoclimate and GCM sources should be evaluated against an appropriately defined null hypothesis. In a simple, univariate setting, such a null hypothesis is usually the spectrum generated by an AR(1) processes. For more complicated systems, or for multivariate cases, a more sophisticated method for generating the null distribution might be needed.

3. Methodologies for comparing decadal variability in proxies and climate models should employ time series analysis and spectral techniques alike. While the former can help isolate the role of external forcings if the temporal evolution of those forcings is known, the latter can identify timescales at which models and proxies exhibit fundamentally different amplitudes of variability.

4. Finally, researchers should consider using forward models of paleoclimate archives to characterize the imprint of proxy systems on the continuum of variability encoded in existing records (e.g., Dee et al., 2015; Dee et al., in revision). Such analyses will help isolate climate, as opposed to non-climate, sources of decadal variability.

An example of how a few of these principles can be applied is shown in Fig. 1 (adapted from Ault et al., 2013). Here NIN03.4 spectra from reconstructions (Emile-Geay et al., 2013) and last millennium model output (OttoBliesner et al., 2016) are compared against the null distribution of ENSO variations with no changes to the external boundary conditions (as in Ault et al., 2013). Here a linear inverse model (LIM) has been used to generate the null distribution (see Ault et al., 2013 and Newman et al., 2011 for details). At the longest resolvable timescales (centuries), the null hypothesis can be rejected for the reconstructions, but not for the model runs. At higher (interannual) frequencies, the reconstructions are well within the null distribution, whereas the model oscillations are not (because this version of the model produces ENSO fluctuations that are too high amplitude in comparison to observations).

While the null hypothesis can be rejected for the centennial timescales in the reconstruction, and the interannual ones in the model, it cannot be rejected for the amplitudes of multidecadal (50-100 year) variations in either data type. This approach could help identify the timescales that require the greatest attention by both paleoclimate and climate modeling research communities to understand the processes responsible for generating low-frequency variability.

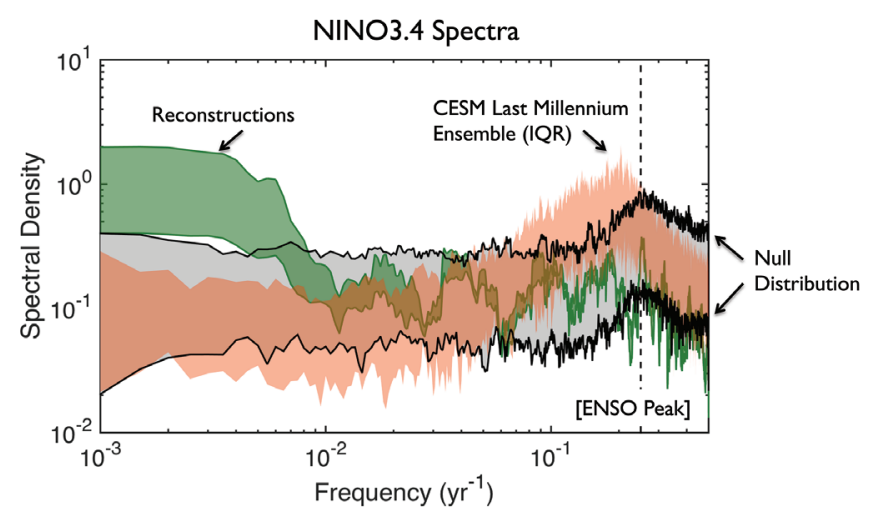

Figure 1: Power spectra of NINO3.4 time series derived from a LIM (black lines with gray shading), multi-proxy paleoclimate reconstructions (green; Emile-Geay et al., 2013), and the CESM Last Millennium Ensemble inner quartile range (IQR) (red; Otto-Bliesner et al., 2016). The vertical dashed line marks the middle of the 2-7 year peak typically associated with ENSO in observations

\section{Acknowledgements}

I would like to thank Scott St. George for helpful suggestions. This work was partially funded by NSF Grant AGS 1602564. 


\section{References}

Ault, T. R., Cole, J. E., Overpeck, J. T., Pederson, G. T., George, S. S., Otto-Bliesner, B., Woodhouse, C. A., and Deser, C. (2013). The continuum of hydroclimate variability in western North America during the last millennium. Journal of Climate.

Coats, S., Smerdon, J. E., Cook, B. I., and Seager, R. (2013). Stationarity of the tropical pacific teleconnection to North America in CMIP5/PMIP3 model simulations. Geophysical Research Letters, 40(18):4927-4932.

Cook, E. R., Woodhouse, C. A., Eakin, C. M., Meko, D. M., and Stahle, D. W. (2004). Long-term aridity changes in the western United States. Science, 306(5698):1015-1018.

Dee, S., Emile-Geay, J., Evans, M. N., Allam, A., Steig, E. J., and Thompson, D. (2015). PRYSM: An open-source framework for PRoxY System Modeling, with applications to oxygenisotope systems. Journal of Advances in Modeling Earth Systems, pages $n / a-n / a$.

Dee, S., Parsons, L., Loope, G., Ault, T., Overpeck, J., and Emile-Geay, J. (under revision for Earth and Planetary Science Letters.). Improved spectral comparisons of paleoclimate models and observations via proxy system modeling: implications for multi-decadal variability.

Emile-Geay, J., Cobb, K. M., Mann, M. E., and Wittenberg, A. T. (2013). Estimating Central Equatorial Pacific SST variability over the Past Millennium. Part 2: Reconstructions and Implications. Journal of Climate.

Evans, M. N., Tolwinski-Ward, S. E., Thompson, D. M., and Anchukaitis, K. J. (2013). Applications of proxy system modeling in high resolution paleoclimatology. Quaternary Science Reviews (accepted).

Franke, J., Frank, D., Raible, C. C., Esper, J., and Broennimann, S. (2013). Spectral biases in tree-ring climate proxies. Nature Climate Change, 3(4):360-364.

Fritts, H. C. (1976). Tree Rings and Climate. Academic Press.

Fritts, H. C., Smith, D. G., Cardis, J. W., and Budelsky, C. A. (1965). Tree-Ring Characteristics Along a Vegetation Gradient in Northern Arizona. Ecology, 46(4):393-401.

MATALAS, N. C. (1962). STATISTICAL PROPERTIES OF TREE RING DATA. International Association of Scientific Hydrology. Bulletin, 7(2):39-47.

Maurer, E. P., Brekke, L., Pruitt, T., and Duffy, P. B. (2007). Fine-resolution climate projections enhance regional climate change impact studies. Eos, Transactions American Geophysical Union, 88(47):504-504.

Meehl, G. A., Goddard, L., Murphy, J., Stouffer, R. J., Boer, G., Danabasoglu, G., Dixon, K., Giorgetta, M. A., Greene,
A. M., Hawkins, E., Hegerl, G., Karoly, D., Keenlyside, N., Kimoto, M., Kirtman, B., Navarra, A., Pulwarty, R., Smith, D., Stammer, D., and Stockdale, T. (2009). Decadal Prediction: Can It Be Skillful? Bulletin of the American Meteorological Society, 90(10):1467+.

Newman, M., Alexander, M. A., Ault, T. R., Cobb, K. M., Deser, C., Di Lorenzo, E., Mantua, N. J., Miller, A. J., Minobe, S., Nakamura, H., Schneider, N., Vimont, D. J., Phillips, A. S., Scott, J. D., and Smith, C. A. (2016). The Pacific Decadal Oscillation, Revisited. Journal of Climate, 29:4399-4427. Otto-Bliesner, B. L., Brady, E. C., Fasullo, J., Jahn, A., Landrum, L., Stevenson, S., Rosenbloom, N., Mai, A., and Strand, G. (2016). Climate Variability and Change since 850 CE: An Ensemble Approach with the Community Earth System Model. Bulletin of the American Meteorological Society, 97(5):735-754.

St. George, S. and Ault, T. R. (2014). The imprint of climate within Northern Hemisphere trees. Quaternary Science Reviews, 89:1-4.

St George, S., Meko, D. M., and Cook, E. R. (2010). The seasonality of precipitation signals embedded within the North American Drought Atlas. Holocene, 20(6):983988.

Tolwinski-Ward, S., Evans, M., Hughes, M., and Anchukaitis, K. (2010). An efficient forward model of the climate controls on interannual variation in tree-ring width. Climate Dynamics, pages 1-21. 